\title{
The Use of Gluconic Acid as an Additive in Magnetic Paper
}

Shaghayegh Rezanezhad,* Nouroeddin Nazarnezhad, Hossein Resalati, and Seyed Majid Zabihzadeh

As magnetic fillers, e.g., nanomagnetite, reduce the mechanical strength of produced magnetic papers, additives should be used. In this study, nanomagnetic papers were produced through an in-situ method by synthesizing magnetic cellulose fibers with kraft fibers and iron salts in a nitrogen atmosphere. Then, gluconic acid was added to improve the mechanical strength. The properties of nanomagnetic papers were investigated via different methods. The nanomagnetite particle size ranged from 1 to $84 \mathrm{~nm}$. Scanning electron microscopy demonstrated the deposited nanomagnetite particles on the surface of the fibers. The saturation magnetization of the nanomagnetic papers treated with $0 \%, 1 \%$, $2 \%$, or $3 \%$ gluconic acid (per dry weight of the pulp) was $7.54,5.64,4.81$, and $0.55 \mathrm{emu} / \mathrm{g}$, respectively. The nanomagnetite particles loaded on the fibers decreased as the gluconic acid content was increased. The nanomagnetic papers exhibited superparamagnetic behavior. Elevation of the gluconic acid content caused an increased tensile and burst index, as well as a reduced tear index. It also led to augmented brightness and diminished opacity.

DOI: 10.15376/biores.17.1.342-354

Keywords: Gluconic acid; Magnetic paper; Mechanical strength; Nanomagnetite; Saturation magnetization

Contact information: Faculty of Natural Resources, Wood and Paper Science Department, Sari Agricultural Sciences and Natural Resource University, P.O. Box 737, Sari 4818168984 Iran;

* Corresponding author: rezanezhad.sh@gmail.com

\section{INTRODUCTION}

Paper is a combination of cellulose fibers, fines, and additives, e.g., fillers, retention and drainage aids, sizing agents, and wet and dry strength additives (Chi et al. 2007; Mohamed et al. 2010; Chauhan and Bhardwaj 2015). Many paper products have been produced with different properties and applications. These properties include thermoresponsive behaviors, conductivity, antibacterial and antifungal properties, self-cleaning effects, or magnetic properties (Biliuta and Coseri 2016). Magnetic papers (MPs) have many applications, e.g., information storage, electromagnetic shielding, magneto-graphic printing, magnetic filtering, and transparent films for magneto-optical application (Chia et al. 2008; Small and Johnston 2009; Fragouli et al. 2012; Nypelö et al. 2014; Kaco et al. 2017; Mo et al. 2017; Rashid et al. 2017).

One of the most important challenges in the papermaking process is the decline in the physical properties of paper when using filler particles, as the particles deposit on the surface of the fibers and reduce hydrogen bonding between fibers (Mo et al. 2017). As such, a paper strength additive should be attached to the fibers and bonded between the 
fibers (Mohamed et al. 2010).

Many studies have been conducted on applying additives to improve the strength of paper. In magnetic papermaking, the nanomagnetite (NM) fillers deposit on the fibers and reduce the strength of the paper (Mohamed et al. 2010). Researchers have studied the use of organic and environmentally friendly materials such as cationic starch as the paper strength additives (Mohamed et al. 2010). However, previous research in magnetic paper production has neglected to consider producing papers with higher strengths. The filler retention improvement approach is the primary reported focus to prepare magnetic papers. Moreover, using other natural and cellulosic derivatives to obtain this aim is important. One of the cellulose derivatives that has remained understudied in papermaking is gluconic acid (GA).

Gluconic acid $\left(\mathrm{C}_{6} \mathrm{H}_{12} \mathrm{O}_{7}\right)$ is a mild organic, noncorrosive, nonvolatile, nontoxic, water soluble, and biodegradable derived acid from glucose obtained through a simple oxidation reaction (Ramachandran et al. 2006; Anastassiadis and Morgunov 2007). Gluconic acid has many applications in various industries (Godjevargova et al. 2004). It is important for chemical and pharmaceutical applications, as well as hygienic products, food, beverage, textile, and other industries (Kim and Kim 1991; Anastassiadis et al. 2003; Ramachandran et al. 2006; Anastassiadis and Morgunov 2007; Singh and Kumar 2007). There are different methods for producing GA, e.g., microbial fermentation and enzymatic, chemical, electrochemical, biochemical, and bio-electrochemical processes (Sankpal and Kulkarni 2002; Ramachandran et al. 2006). Due to the organic structure of GA and its similarity to glucose in the cellulose chain, as well as the carboxyl and hydroxyl groups in its structure, it can be a good candidate to be used as a paper strength additive.

The purpose of this paper is to investigate and introduce a GA additive into papermaking and determine its efficiency in increasing the strength of nanomagnetic papers (NMPs) produced with kraft fibers (KF) and nanomagnetite (NM) via in-situ synthesis. Chitosan and epichlorohydrin were also added as cross-linking additives in the synthesis phase of the magnetic fibers, to cause homogeneous dispersion of the NM onto the surface of the fibers and iron salts, as well as during the process. The morphology of the fibers, paper strength, optical properties, and saturation magnetization of the paper were studied before and after the magnetization process.

\section{EXPERIMENTAL}

\section{Materials}

Commercial hardwood kraft fibers were supplied from the wood and paper industry Mazandaran Co., Ltd. (Sari, Iran). Iron dichloride tetrahydrate $\left(\mathrm{FeCl}_{2} \cdot 4 \mathrm{H}_{2} \mathrm{O}, 98.0 \%\right.$ purity), iron trichloride hexahydrate $\left(\mathrm{FeCl}_{3} \cdot 6 \mathrm{H}_{2} \mathrm{O}, 98.0 \%\right.$ purity), ammonium hydroxide solution $\left(\mathrm{NH}_{4} \mathrm{OH}, 28.0 \%\right)$, and epichlorohydrin $\left(\mathrm{C}_{3} \mathrm{H}_{5} \mathrm{CLO}\right)$ were purchased from Merck \& Co. (Kenilworth, NJ). Chitosan $\left(\mathrm{C}_{6} \mathrm{H}_{11} \mathrm{NO}_{4}\right)$ with a medium molecular weight (190000 Da to $310000 \mathrm{Da}$ ) was purchased from Sigma-Aldrich (St. Louis, MO) and the gluconic acid solution $\left(\mathrm{C}_{6} \mathrm{H}_{12} \mathrm{O}_{7}, 50.0 \%\right)$ with a molecular weight of $196.16(\mathrm{~g} / \mathrm{mol})$ was purchased from Samchun Pure Chemical Co. Ltd. (Pyeongtaek-si, South Korea).

\section{Preparation of the cellulose fibers}

The KF sheets were soaked in water for $24 \mathrm{~h}$, and then the pulp fibers were obtained using a laboratory pulp disintegrator to a freeness of $300 \mathrm{CSF} \pm 20 \mathrm{CSF}$. 


\section{Production of the nanomagnetic fibers}

The magnetic fibers were synthesized using the method of Cao et al. (2015). $\mathrm{FeCl}_{2} \cdot 4 \mathrm{H}_{2} \mathrm{O}(0.5 \mathrm{~g}), \mathrm{FeCl}_{3} \cdot 6 \mathrm{H}_{2} \mathrm{O}(1 \mathrm{~g})$, chitosan $(0.6 \mathrm{~g})$, epichlorohydrin $(2 \%$ per the dry weight of the pulp), and gluconic acid in different values $(0 \%, 1 \%, 2 \%$, or $3 \%$ per the dry weight of pulp) were dissolved in $200 \mathrm{~mL}$ of $1.5 \mathrm{wt} . \%$ aqueous suspension of cellulose fibers under a nitrogen flow. Then, $\mathrm{NH}_{4} \mathrm{OH}$ was added until a $\mathrm{pH}$ of 11 was reached under continuous stirring at a temperature of $40{ }^{\circ} \mathrm{C}$ for $30 \mathrm{~min}$. Finally, the magnetic fiber was washed with distilled water.

\section{Production of the magnetic hand-sheet}

The KF and NM hand-sheet with a $120 \mathrm{~g} / \mathrm{cm}^{2}$ basis weight was formed according to TAPPI standard T205 (2002).

\section{Methods}

Determination of the mechanical properties of the papers, including the tensile, burst, tearing strengths, and apparent density were measured according to TAPPI standard T494 (2001), TAPPI standard T403 (2002), TAPPI standard T414 (2004), and TAPPI standard T220 (2001), respectively. The optical properties, i.e., the brightness and opacity, were measured according to TAPPI standard T452 (2002) and TAPPI standard T425 (2001), respectively. The ash content of the paper was measured according to TAPPI standard T211 (2002). It was calculated using Eq. 1,

$$
\mathrm{Ash}=A \times 100 / B
$$

where $A$ and $B$ are the moisture-free weight of the ash $(\mathrm{g})$ and moisture-free weight of the sample $(\mathrm{g})$, respectively.

X-ray diffraction (XRD) analysis was performed on all samples using a X' Pert MPD, Philips diffractometer. The samples were scanned with $\mathrm{Cu} \mathrm{K \alpha}=1.5406 \AA$ radiation at a diffraction angle $(2 \theta)$ ranging from $5^{\circ}$ to $80^{\circ}$ and a step size of $1 \% \mathrm{~min}$. Atomic force microscopy (AFM) was used to determine the size of the NM particles. The AFM was performed with an Easyscan2 Flex AFM probe microscope in air. The samples were prepared by dispersing $1 \mathrm{mg}$ of NM in distilled water via an ultrasonic bath for $10 \mathrm{~min}$. A droplet of the NM solution was cast onto a microscope slide. The morphology of the NM particles and fibers, as well as the fibers after magnetic treatment, were examined via scanning electron microscopy (SEM). The SEM micrographs of the samples were taken using a SEC-SNE-4500 scanning electron microscope. The samples were covered with a thin layer of gold via sputtering. The magnetization of the samples was measured via vibrating sample magnetometry (VSM) using a Meghnatic Daghigh Kavir company device in an applied magnetic field sweeping between \pm 10000 Oe.

\section{RESULTS AND DISCUSSION}

\section{Scanning Electron Microscopy (SEM) and Atomic Force Microscopy (AFM) Characterizations}

The surface morphology and particle size of the $\mathrm{Fe}_{3} \mathrm{O}_{4}$ nanoparticles, fibers, and magnetic fibers were observed via AFM and SEM. Figure 1 reveals the AFM and SEM micrographs. Figure 1d displays the uniform cubic structures of $\mathrm{Fe}_{3} \mathrm{O}_{4}$. The observed arrangement of particles may be due to the aggregation phenomenon in the nanomagnetite 
particles after drying in the paper structure. Nanomagnetite particles tend to accumulate because of the strong magnetic attraction, van der Waals forces, and the high energy of the surface of the particles (Ali et al. 2016). Figure 1e shows the cellulose fibers before magnetic treatment. Figure 1f shows the magnetic fibers after magnetic treatment, which indicated that the $\mathrm{Fe}_{3} \mathrm{O}_{4}$ nanoparticles had been deposited onto the fibers. After the in-situ synthesis of the $\mathrm{Fe}_{3} \mathrm{O}_{4}$ nanoparticles, many clustered particles were present, which could be clearly observed on the surface of the magnetic fibers (as shown in Fig. $2 \mathrm{f}$ by the arrows). These images indicated that after loading the magnetite, the surface of the fibers tended to become rough and the surface of the fibers was altered. The frequency of the nanomagnetite particles size was measured via AFM. Figures 1a through Fig. 1c showed the AFM image, particle size distribution diagram, and 3D topography of $\mathrm{Fe}_{3} \mathrm{O}_{4}$. The nanomagnetite particle size ranged from $1 \mathrm{~nm}$ to $84 \mathrm{~nm}$.
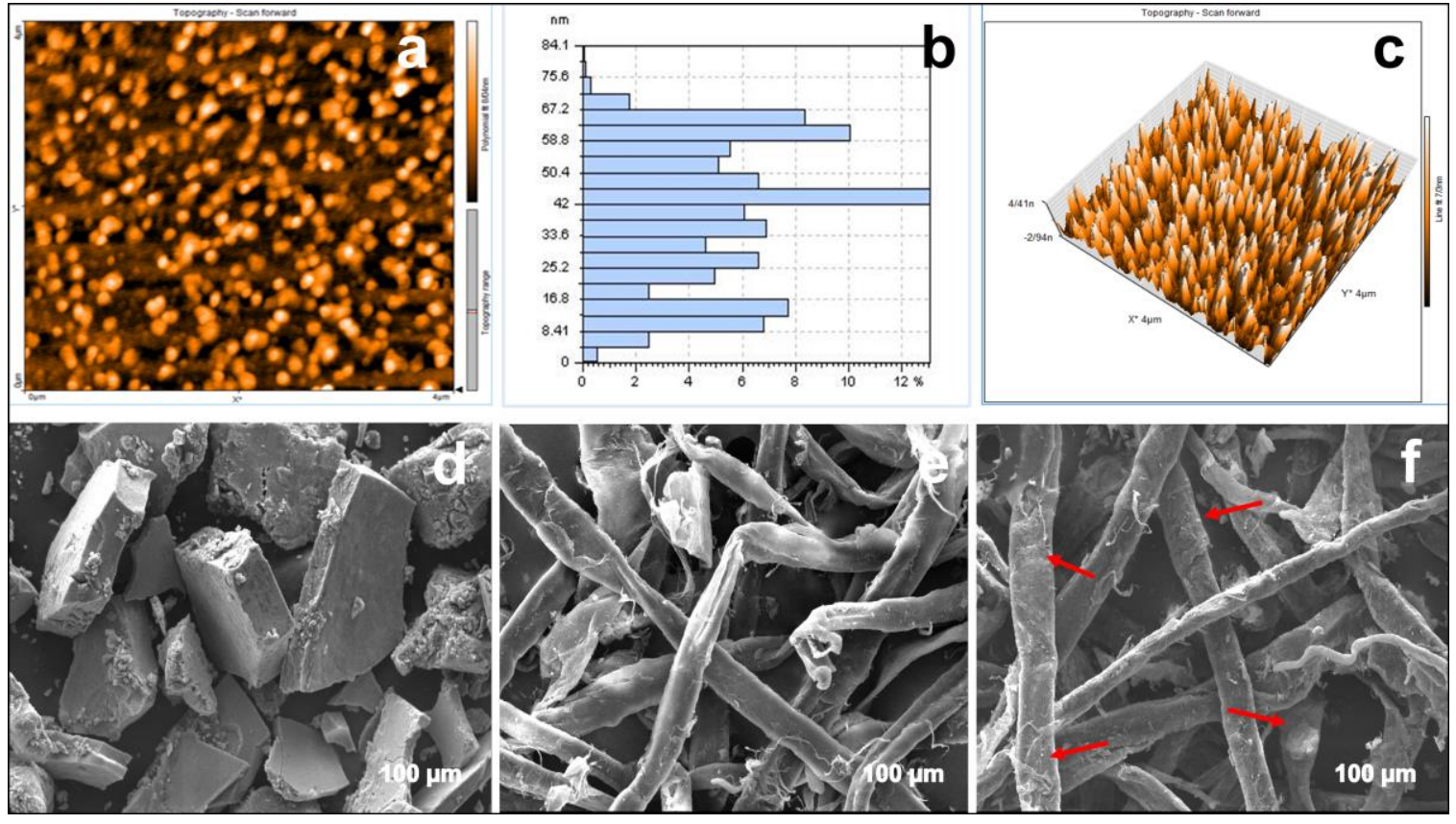

Fig. 1. The AFM image of the surface topography (a); the frequency of the particles diameter distribution diagram (b); the 3D topography of NM (c); the SEM image of the NM particles (d); the cellulose fiber (e); and the surface of magnetic fiber after GA treatment ( $f$ )

\section{Determination of Ash Content (Filler Content) and Apparent Density}

The ash content and apparent density of the nano magnetic paper with $0 \%$ GA was used as the control sample, and the nano magnetic papers with different GA treatments are shown in Fig. 2. The control sample had the highest ash content, and the ash content of the treated samples diminished as the GA content increased. During in-situ synthesis, the white color of the fibers changed due to the black color of the nanomagnetite (Chia et al. 2008). The color of the nano magnetic papers became lighter upon reduction of the ash content. The apparent density of samples was increased by decreasing the GA value in the magnetic papers. The apparent density of papers is a critical parameter that impact other properties of paper (Santos et al. 2008a,b). Tensile strength increased with increasing density of paper (Seth and Kingsland 1990). 


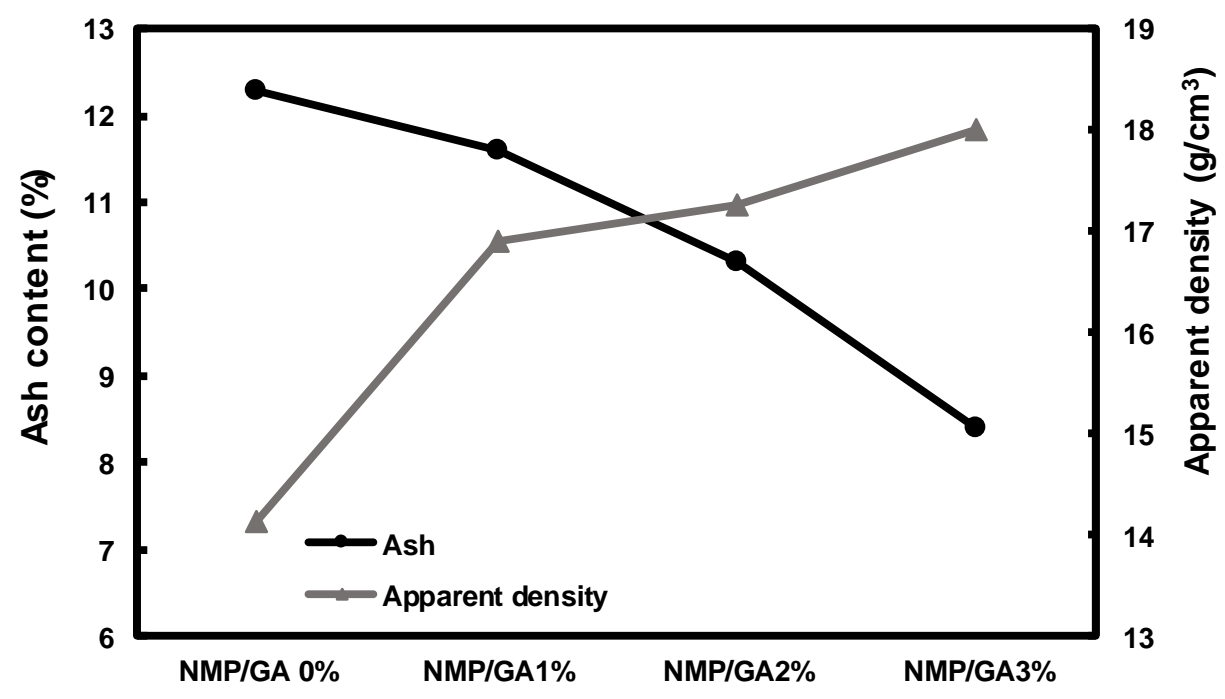

Fig. 2. Ash content and apparent density in the NMPs with a $0 \%, 1 \%, 2 \%$, or $3 \%$ GA treatment

\section{The Effect of Gluconic Acid (GA) on the Papers and the Strength Properties of the Nanomagnetic Papers (NMPs)}

The tensile, burst, and tear strengths of the nano magnetic papers samples were tested using a tensile test, burst test, and tearing test machine at room temperature. Initially, the paper samples with $0 \%, 1 \%, 2 \%$, or $3 \%$ GA were produced in order to verify the ability of GA to improve the strength of papers. Figure 3 shows the diagrams of the tensile, burst, and tear index of the control sample and nano magnetic papers treated with $0 \%, 1 \%, 2 \%$, or $3 \%$ GA. Chitosan and epichlorohydrin were used to produce the samples. Epichlorohydrin increases fibers bonds with covalent bonds as well as increases fiber flocculation. Increasing the flocculation causes improvements in paper formation and as a result, the paper strength improves. In addition, chitosan increases the fiber bonding, and the paper strength increases, subsequently. Cellulose fibers become anionic after being immersed in water (Burkinshaw 2016). The electrostatic force attracts anionic fibers and cationic iron salts together in the aqueous solution. After the formation of the nanomagnetite, these particles form hydrogen bonds with cellulose through their surface hydroxyl groups. They also react with the chitosan amine groups and fill the reactive sites of the fibers and the chitosan. As a result, the amount of bonding is reduced, thereby reducing the strength of the paper. The nanomagnetite acts as a filler between the fibers and prevents bonding between the fibers, which as a result reduces the strength (Zakaria et al. 2004). The strength increased for the nano magnetic papers with addition of GA in the production process of the magnetic fibers.

The tensile and burst strength are influenced by several factors, e.g., the bonding between the fibers, bonding strength, number of bonds, paper sheet formation, and fiber bonded surface (Maurer and Kearney 1998; Zakaria et al. 2005). The bond type between the fibers in the paper was hydrogen bonding. Due to the hydroxyl and carboxyl functional groups of the GA, the bond between the fibers was increased by creating connections of the type fiber to fiber and fiber to GA. Zakaria et al. (2005) and Chia et al. (2008) also confirmed the impact of the presence of the reactive hydroxyl and carboxyl groups on increasing the inter-fiber bonds. Chitosan, as a polymer, is similar to cellulose, and increases the strength of non-magnetite paper. The tear strength is mostly influenced by 
the strength of each fiber, the length of the fibers in comparison to bonding between fibers, and the ratio between the long fibers to short fibers in the paper, thus, increasing the amount of GA resulted in an increase in small particles in comparison to long fibers in the paper; as a result, the paper tear strength decreased (Khalilian et al. 2018).
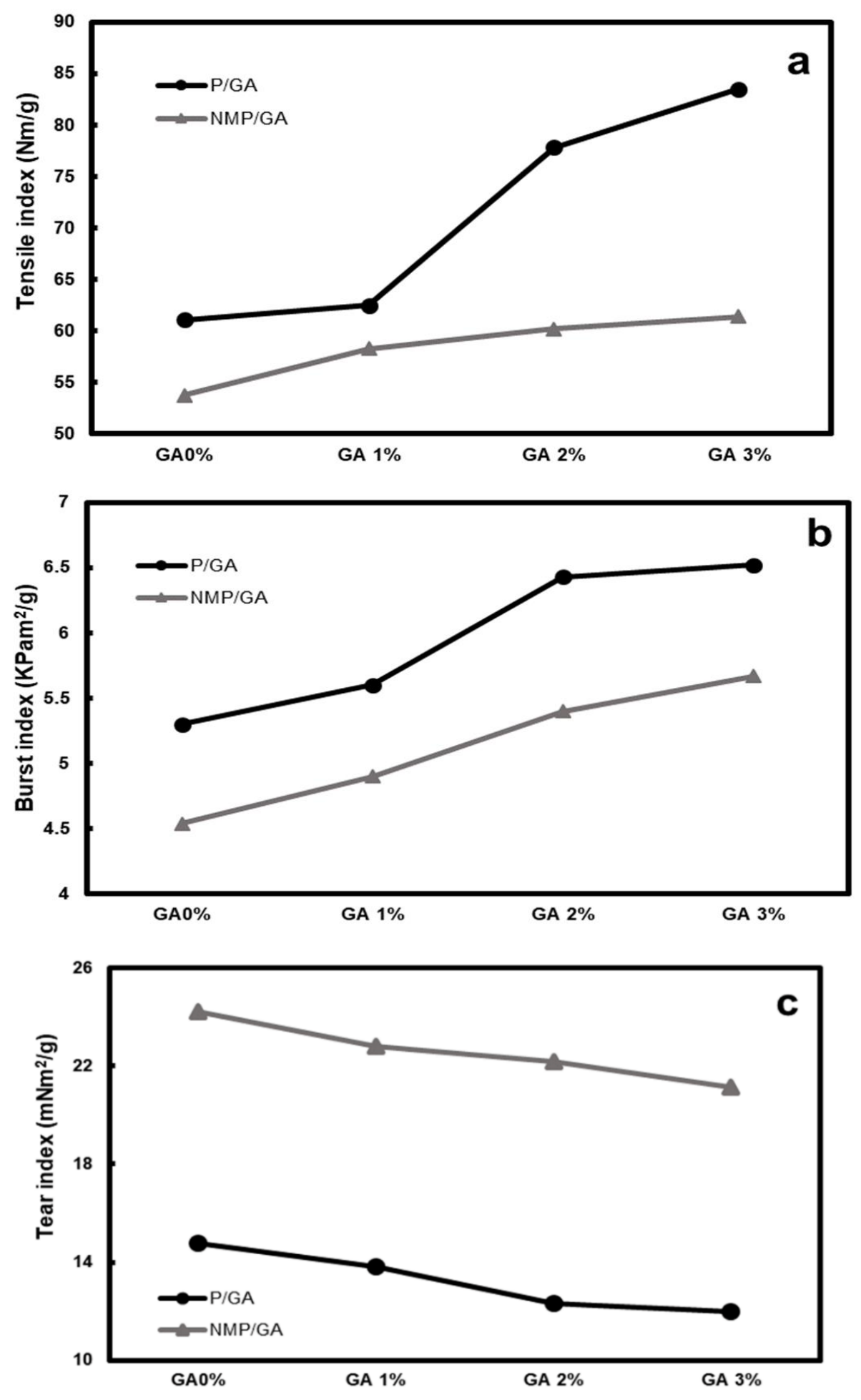

Fig. 3. Tensile index (a); burst index (b); and tear index (c) of KF paper with $G A(P / G A)$ and the NMPs with a $0 \%, 1 \%, 2 \%$, or $3 \%$ GA treatment (NMP/GA) 


\section{Optical Properties of the Papers}

Figure 4 shows the optical properties of the samples. The nano magnetic paper with $3 \%$ GA had the highest brightness, although there was little difference between the nano magnetic paper samples. Fillers are used to improve the opacity and brightness of the papers (Song et al. 2009; Zhang et al. 2014).
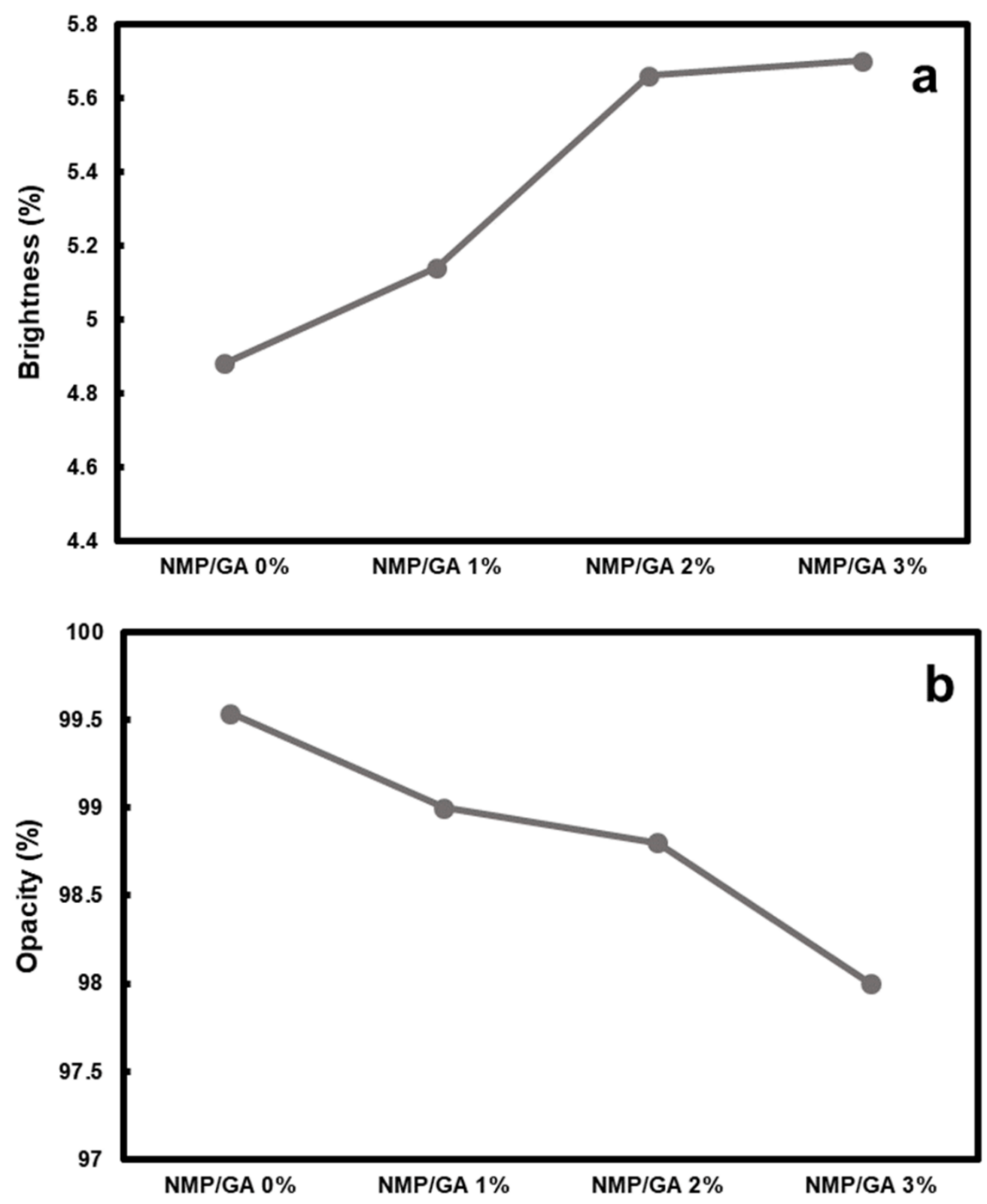

Fig. 4. Brightness (a) and opacity (b) of the NMPs with a $0 \%, 1 \%, 2 \%$, or $3 \%$ GA treatment

Nanomagnetite particles can reduce the brightness of the papers due to the black color. The brightness increased as the percentage of GA increased, i.e., from $0 \%$ to $3 \%$. In addition, the change in color of the paper made with nano magnetic papers confirmed the increasing brightness. The color of the nano magnetic papers became darker upon the reduction of the GA content. The opacity diagram indicated that the NMP without GA has the highest opacity. Fillers improve the optical properties of paper by moving forward the 
light scattering capacity through expanding the specific surface area (Farnood 2009). In addition, the opacity of the nano magnetic papers samples decreased as the GA content decreased in the samples, which indicated that the amount of filler had decreased. The light scattering ability of the papers can be attributed to the bonding between the fibers (Hubbe 2006). The opacity was decreased due to increasing bonding between fibers. As a result, the magnetic paper with higher tensile strength illustrated lower opacity.

\section{XRD (X-ray Diffraction)}

Figure 5 depicts the X-ray diffraction patterns of the nanomagnetite, cellulose fibers, and nano magnetic papers. The XRD for the nanomagnetite had six primary diffraction peaks at $26.30^{\circ}, 35.6^{\circ}, 41.26^{\circ}, 53.7^{\circ}, 62.18^{\circ}$, and $74.46^{\circ}$, which refers to the $\mathrm{Fe}_{3} \mathrm{O}_{4}$ nanoparticles (Long et al. 2009; Small and Johnston 2009). The pattern exhibited a sharp peak at $35^{\circ}$, and this peak decreased after the in-situ synthesis of the nanomagnetite and fibers. The diffraction pattern of the cellulose fibers showed two intense diffraction peaks at approximately $2 \theta=16^{\circ}$ and $22.61^{\circ}$, which were assigned to the cellulose type - I (Mashkour et al. 2011; Wu et al. 2011; Cao et al. 2015). The primary peak of cellulose increased as the GA content increased in the samples. Diffraction peaks for the nano magnetic paper with GA treatment samples were found at $17^{\circ}, 22^{\circ}, 35^{\circ}$, and $41^{\circ}$, which were associated with both cellulose and $\mathrm{Fe}_{3} \mathrm{O}_{4}$, and were observed in all samples treated with nanomagnetite. As shown in the XRD patterns, the primary peaks of NM decreased as the GA content increased. Iron oxide has different structures, e.g., magnetite $\left(\mathrm{Fe}_{3} \mathrm{O}_{4}\right)$, maghemite $\left(\alpha-\mathrm{Fe}_{2} \mathrm{O}_{3}\right)$, hematite $\left(\gamma-\mathrm{Fe}_{2} \mathrm{O}_{3}\right)$, and ferric hydroxide $(\beta-\mathrm{FeOOH})$ (Zboril et al. 2002). The diffraction peaks observed in the XRD indicated that the produced iron oxide was magnetite.

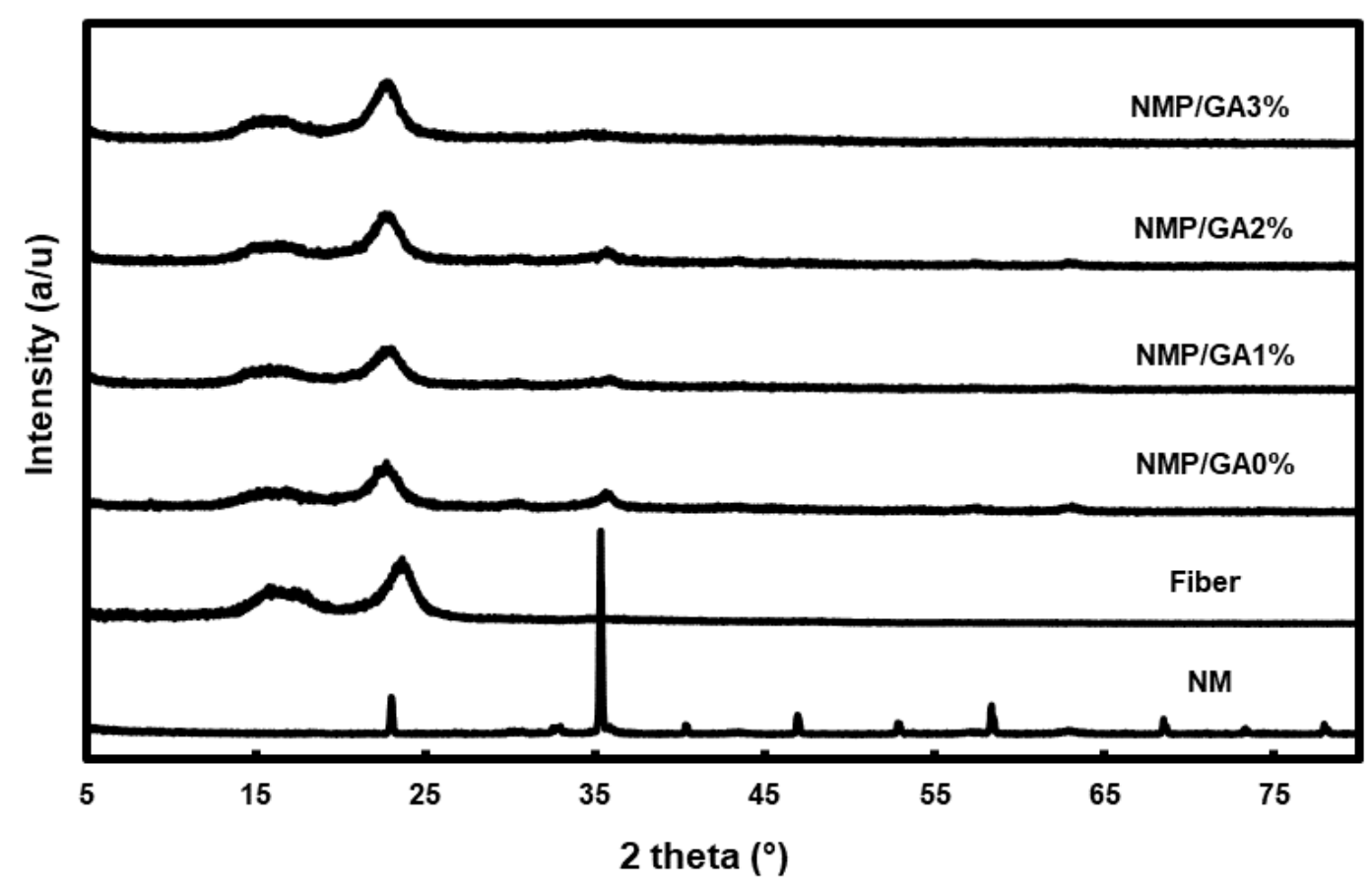

Fig. 5. XRD diffraction patterns of the NM, fiber, and NMPs with a $0 \%, 1 \%$, $2 \%$, or $3 \%$ GA treatment 


\section{Magnetic Properties}

The magnetic behavior of the nanomagnetite and nano magnetic papers was examined via vibrating sample magnetometry (VSM), at room temperature. Figure 6 indicated that the nano magnetic paper samples exhibited superparamagnetic behavior, as confirmed by the absence of coercivity $(\mathrm{Hc})$, remanence $(\mathrm{Mr})$, and ferromagnetic behavior (Mashkour et al. 2011; Biliuta and Coseri 2016). The saturation of the magnetization value for the nano magnetic papers with a $0 \%, 1 \%, 2 \%$, or $3 \%$ GA treatment was 7.54, 5.64, 4.81, and $0.55 \mathrm{emu} / \mathrm{g}$, respectively. As a result, the magnetic particles loaded into the cellulose fibers diminished as the GA value was increased. The GA reactivity was high due to its hydroxyl and carboxyl functional groups in its structure. The addition of GA in the in-situ synthesis process of the magnetic fibers acted as a competitor to the nanomagnetite and caused a reaction between the GA and hydroxyl groups of cellulose and the chitosan amine groups, thus filling their reactive sites. This prevented the nanomagnetite from reacting with them, causing the magnetite particles to be suspended in the system, and then removed during the papermaking process. Furthermore, the GA reacts with the nanomagnetite and bonds through hydroxyl groups. However, the GA is a small monomer and may be removed from the fiber suspension when making paper. As a result, the magnetic saturation in the final paper was reduced. Hence, the magnetic saturation in the nano magnetic papers decreased as the GA increased.

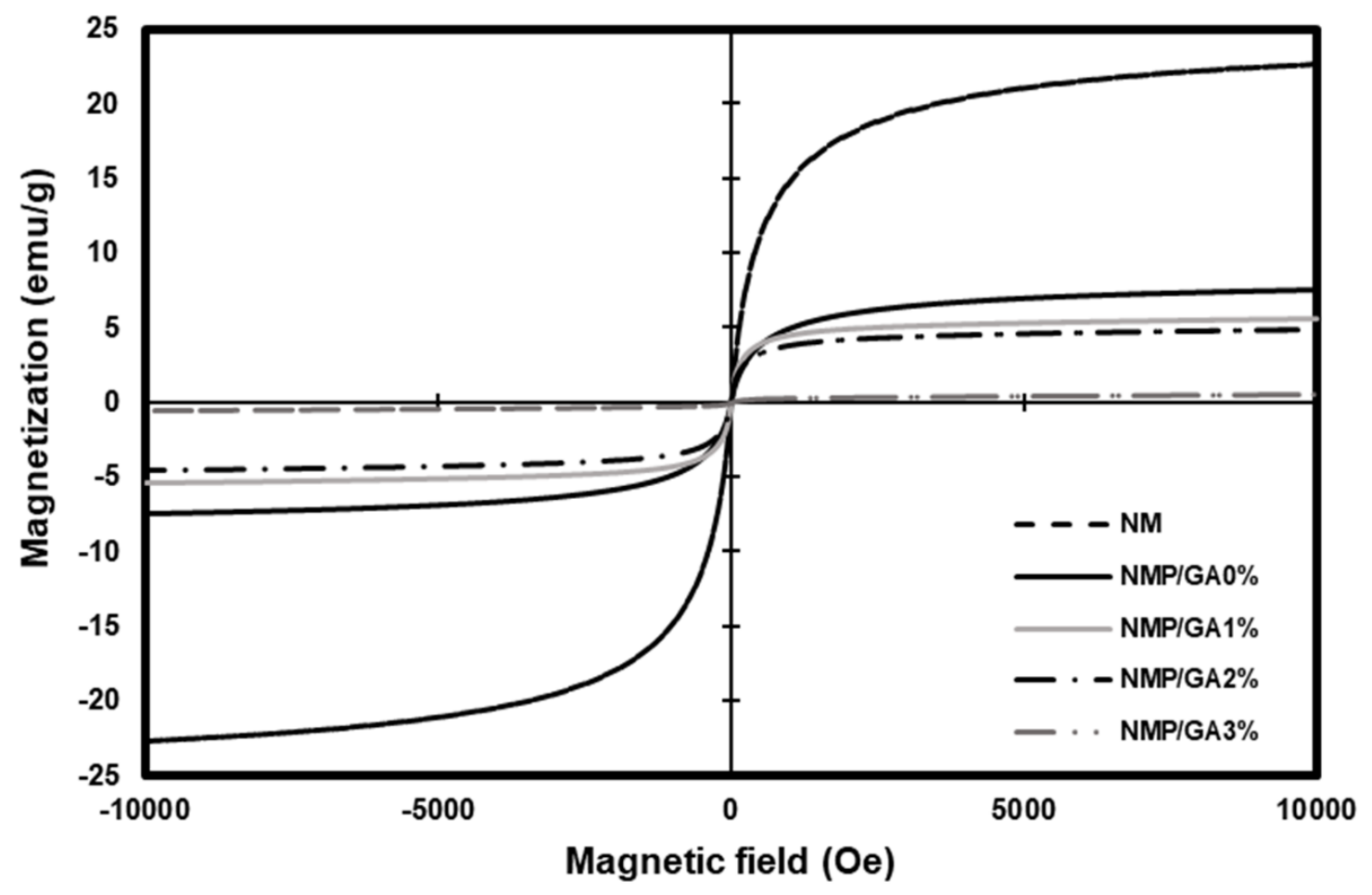

Fig. 6. Hysteresis loops of the NM and NMPs with a $0 \%, 1 \%, 2 \%$, or $3 \%$ GA treatment 


\section{CONCLUSIONS}

1. The utilization of gluconic acid (GA) as an additive improved the tensile and burst index of the nano magnetic papers.

2. The addition of GA reduced the retention of nanomagnetite on the fiber surface and resulted in a diminished ash content and saturation magnetization.

3. The optical properties of the paper made from kraft fibers (KF) as well as the nano magnetic papers indicated that the brightness of the nano magnetic papers was increased by decreasing the magnetization and ash content, while the opacity decreased by decreasing the magnetization.

\section{ACKNOWLEDGMENTS}

The authors are grateful to the Sari Agricultural Science and Natural Resources University for providing equipment support.

\section{REFERENCES CITED}

Ali, A., Zafar, H., Zia, M., Haq, I. u., Phull, A. R., Ali, J. S., and Hussian, A. (2016). "Synthesis, characterization, applications, and challenges of iron oxide nanoparticles," Nanotechnology, Science and Applications 9, 49-67. DOI: 10.2147/NSA.S99986

Anastassiadis, S., Aivasidis, A., and Wandrey, C. (2003). "Continuous gluconic acid production by isolated yeast-like mould strains of Aureobasidium pullulans," Applied Microbiology and Biotechnology 61, 110-117. DOI: 10.1007/s00253-002-1180-8

Anastassiadis, S., and Morgunov, I. G. (2007). "Gluconic acid production," Recent Patents on Biotechnology 1(2), 1-14. DOI: 10.2174/187220807780809472

Biliuta, G., and Coseri, S. (2016). "Magnetic cellulosic materials based on TEMPO oxidized viscose fibers," Cellulose 23(6), 3407-3415. DOI: 10.1007/s10570-0161082-z

Burkinshaw, S. M. (2016). "Cellulosic fibers," in: Textbook of Physico-chemical aspect of textile coloration, Wiley, Hoboken, NJ. DOI: 10.1002/9781118725658

Cao, S.-L., Xu, H., Li, X.-H., Lou, W.-Y., and Zong, M.-H. (2015). "Papain@magnetic nanocrystalline cellulose nanobiocatalyst: A highly efficient biocatalyst for dipeptide biosynthesis in deep eutectic solvents," ACS Sustainable Chemistry and Engineering 3(7), 1589-1599. DOI: 10.1021/acssuschemeng.5b00290

Chauhan, V. S., and Bhardwaj, N. K. (2015). "Efficacy of carbohydrate polymers in filler pre flocculation for use in papermaking," Arabian Journal of Chemistry 12(8), 1-9. DOI: 10.1016/j.arabjc.2015.08.002

Chi, H., Li, H., Liu, W., and Zhan, H. (2007). "The retention- and drainage-aid behavior of quaternary chitosan in papermaking system," Colloids and Surfaces A:

Physicochemical and Engineering Aspects 297(1-3), 147-153. DOI:

10.1016/j.colsurfa.2006.10.039

Chia, C. H., Zakaria, S., Nguyen, K. L., and Abdullah, M. (2008). "Utilization of unbleached kenaf fibers for preparation of magnetic paper," Industrial Crops and 
Products 28(3), 333-339. DOI: 10.1016/j.indcrop.2008.03.012

Farnood, R. (2009). "Review: Optical properties of paper: Theory and practice," In Advances in Pulp and Paper Research, Oxford, FRC, Manchester, UK, 273-352. DOI: 10.15376/frc.2009.1.273

Fragouli, D., Bayer, I. S., Corato, R. D., Brescia, R., Bertoni, G., Innocenti, C., Gatteschi, D., Pellegrino, T., Cingolani, R., and Athanassiou, A. (2012). "Superparamagnetic cellulose fiber networks via nanocomposite functionalization," Journal of Materials Chemistry 22(4), 1662-1666. DOI: 10.1039/c1jm14755b

Godjevargova, T., Dayal, R., and Turmanova, S. (2004). "Gluconic acid production in bioreactor with immobilized glucose oxidase plus catalase on polymer membrane adjacent to anion-exchange membrane," Macromolecular Bioscience 4(10), 950-956. DOI: $10.1002 / \mathrm{mabi} .200400058$

Hubbe, M. (2006). "Bonding between cellulosic fibers in the absence and presence of dry-strength agent-A review," BioResources 1(2), 281-318. DOI:

10.15376/biores.1.2.281-318

Kaco, H., Baharin, K. B., Zakaria, S., Chia, C. H., Sajab, M. S. Jaafar, S. N. S., and Gan, Y. S. (2017). "Preparation and characterization of $\mathrm{Fe}_{3} \mathrm{O}_{4} /$ regenerated cellulose membrane," Sains Malaysiana 46(4), 623-628. DOI: 10.17576/jsm-2017-4604-15

Kim, D.-M., and Kim, H.-S. (1991). "Continuous production of gluconic acid and sorbitol from Jerusalem artichoke and glucose using an oxidoreductase of Zymomonas mobilis and lnulinase," Biotechnology and Bioenergy 39(3), 336-342. DOI: 10.1002/bit.260390312

Long, Z., Li, H. F., Yang, X., and Liang, H. N. (2009). "Study on preparation and characterization of magnetic paper with bleached chemical pulp," in: Proceedings of the $2^{\text {nd }}$ International Congress on Image and Signal Processing, 17-19 October, Tianjin, China, pp. 4131-4244.

Mashkour, M., Tajvidi, M., Kimura, T., Kimura, F., and Ebrahmi, G. (2011). "Fabricating unidirectional magnetic papers using permanent magnets to align magnetic nanoparticles covered natural cellulose fibers," BioResources 6(4), 47314738. DOI: 10.15376/biores.6.4.4731-4738

Maurer, H. W., and Kearney, R. L. (1998). "Opportunities and challenges for starch in the paper industry," Starch 50(9), 396-402. DOI: 10.1002/(SICI)1521-379X (199809)50:9<396: AID-STAR396>3.0.CO;2-8

Mo, Z., Gou, H., Wang, Y., Yin, H., Yang, C., and Song, J. (2017). "Surface modification of graphene oxide sheets on magnetic particles for magnetic paper," Journal of Alloys and Compounds 695, 2525-2531. DOI: 10.1016/j.jallcom.2016.11.157

Mohamed, A. Z., Zakaria, S., Shamsudin, R., and Abdullah, M. H. J. (2010). "Cationic starch as a dry strength agent in magnetic papermaking," Sains Malaysiana 39(2), 239-242.

Nypelö, T., Rodriguez-Abreu, C., Rivas, J., Dickey, M. D., and Rojas, O. J. (2014). "Magneto-responsive hybrid materials based on cellulose nanocrystals," Cellulose 21, 2557-2566. DOI: 10.1007/s10570-014-0307-2

Ramachandran, S., Fontalline, P., Pandey, A., and Larroche, C. (2006). "Gluconic acid: Properties, applications and microbial production," Food Science and Biotechnology 44(2), 185-195.

Rashid, M., Ghafur, M. A., Sharafat, K. M., Minami, H., Miah, M. A. J., and Ahmad, H. (2017). "Biocompatible microcrystalline cellulose particles from cotton wool and 
magnetization via a simple in situ co-precipitation method.," Carbohydrate Polymer 170, 72-79. DOI: 10.1016/j.carbpol.2017.04.059

Sankpal, N. V., and Kulkarni, B. D. (2002). “Optimization of fermentation conditions for gluconic acid production using Aspergillus niger immobilized on cellulose microfibrils," Process Biochemistry 37(12), 1343-1350. DOI: 10.1016/S00329592(01)00335-1

Santos, A., Amaral, M., Vaz, A., Anjos, O., and Simões, R. (2008a). "Effect of Eucalyptus globulus wood density on papermaking potential," TAPPI Journal 7(5), 25-32.

Santos, A., Anjos, O., and Simões, R. (2008b). "Influence of kraft cooking conditions on the pulp quality of Eucalyptus globulus," The Australasian Pulp and Paper Technical Association Journal 61(2), 148-155.

Seth, R., and Kingsland, M. (1990). "The reinforcing properties of softwood kraft pulps," Pulp and Paper Canada 91(7), 68-72, 74-75.

Khalilian, M. K., Moradian, M. H., and Charani, P. R. (2018). "Improving wet tensile strength of paper glass using PAE, CNF and CMC," Iranian Journal of Wood and Paper Industries 9(2), 163-173.

Singh, O. V., and Kumar, R. (2007). "Biotechnological production of gluconic acid: Future implications," Applied Microbiology and Biotechnology 75, 713-722. DOI: 10.1007/s00253-007-0851-X

Small, A. C., and Johnston, J. H. (2009). "Novel hybrid materials of magnetic nanoparticles and cellulose fibers," Journal of Colloid and Interface Science 331(1), 122-126. DOI: 10.1016/j.jcis.2008.11.038

Song, D., Dong, C., Ragauskas, A., and Deng, Y. (2009). "Filler modification with polysaccharides or their derivatives for improved paper properties," Journal of Biobased Materials and Bioenergy 3(4), 321-334. DOI: 10.1166/jbmb.2009.1042

TAPPI T205 (2002). "Forming hand-sheets for physical tests of pulp," TAPPI Press, Atlanta, GA.

TAPPI T211 (2002). "Ash in wood, pulp, paper and paperboard: combustion at 525 degrees C," TAPPI Press, Atlanta, GA.

TAPPI T220 (2001). "Physical testing of pulp handsheets," TAPPI Press, Atlanta, GA.

TAPPI T403 (2002). "Bursting strength of paper," TAPPI Press, Atlanta, GA.

TAPPI T414 (2004). "Internal tearing resistance of paper (Elmendorf-type method)," TAPPI Press, Atlanta, GA.

TAPPI T425 (2001). "Opacity of paper (15/d geometry, illuminant A/2o, 89\% reflectance backing and paper backing)," TAPPI Press, Atlanta, GA.

TAPPI T452 (2002). "Brightness of pulp, paper, and paperboard (directional reflectance at $457 \mathrm{~nm})$, , TAPPI Press, Atlanta, GA.

TAPPI T494 (2001). "Tensile properties of paper and paperboard (using constant rate of elongation apparatus)," TAPPI Press, Atlanta, GA.

Wu, W.-B., Jing, Y., Gong, M.-R., Zhou, X.-F., and Dai, H.-Q. (2011). "Preparation and properties of magnetic cellulose fiber composites," BioResources 6(3), 3396-3409.

DOI: 10.15376/biores.6.3.3396-3409

Zakaria, S., Ong, B. H., Ahmad, S. H., Abdullah, M., and Yamauchi, T. (2005). "Preparation of lumen-loaded kenaf pulp with magnetite $\left(\mathrm{Fe}_{3} \mathrm{O}_{4}\right)$," Materials Chemistry and Physics 89(2-3), 216-220. DOI: 10.1016/j.matchemphys.2003.12.026

Zakaria, S., Ong, B. H., and van de Ven, T. G. M. (2004). "Lumen loading magnetic paper 1: flocculation," Colloids and Surfaces A: Physicochemical and Engineering 
Aspects 251(1-3), 1-4. DOI: 10.1016/j.colsurfa.2004.06.020

Zboril, R., Mashlan, M., and Petridis, D. (2002). "Iron(III) oxides from thermal processes - Synthesis, structural and magnetic properties, Mössbauer spectroscopy characterization, and applications," Chemistry of Materials 14(3), 969-982. DOI: $10.1021 / \mathrm{cm} 0111074$

Zhang, M., Hao, N., Song, S., Wang, J., Wu, Y., and Li, L. (2014). "Investigation of the mixed refining of a novel fly ash-based calcium Silicate filler with fiber," BioResources 9(3), 5175-5183. DOI: 10.1021/ie3028813

Article submitted: September 29, 2021; Peer review completed: November 6, 2021; Revised version received and accepted: November 14, 2021; Published: November 18, 2021.

DOI: $10.15376 /$ biores.17.1.342-354 